research. Disease was clinically a disturbance of the normal play of the functions, causing pain, weakness, malaise, and biliousness, as was demonstrated by the phenomens of special diseases, but serious diseases often lay latent tefore developing clinical symptoms. Organic changes wero marked in some diseases, apparently absent in others; but, after all, such changes would probably be detected in the latter class by further investigations. Disease was an abstract term, and it might imply disorder, sutforing and loss of function easily accounted for by injury to or changes in organs and tissues, yet the term must also be applied to similar unfavourable subjective conditions not to be traced to visible injuries and changes; and lastly, morbid changes in structures may be independent of any symptoms.

The complexity of the causes of disease, and the difficulty of tracing them, was next considered. The beginning of an intelligent study of pathological anatomy was traced to Morgagni's DC Sedibus et Cinusis Morborum per Anatomen indagatis, a work based upon a long series of necropsies made by himself and his master Valsalva. Morbid states of the blood were then discussed. Besides anæmia, spanæmia, leuco cythemia, hyperæmia, and forms of blood-poisoning where mineral poisons were really found in the blood, there were also the morbid conditions where specific germs existed, and diseases where forms of life much higher than bacteria were found in the circulation. Reference was then made to the opinions of Panum, Burdon Sanderson, Bergmann and Koch, as to the precise relation of micro-organisms to the infection which they were said to produce, but with which they may only be associated. Dr. Eaton named the principal micro-organisms which had been considered as truly specific, and then gave a succinct acconnt of Pasteur's work. Pathogenic bacilli, as well as the reputed essentially specific forms, were then named in association with the conditions in which they were found.

Notice was then taken of inflammatory products, textural changes and degenerations, new growths, and animal and vegetable parasites. These latter were described at some length, in an instructive manner. Malformations were also discussed. Then some words were said on the predisposing causes of disease, and the influence of age, sex, temperament, diet, occupation, heredity, intermarriage, previous attacks of disease, mental, moral and physical conditions, hygienic surroundings, temperature, atmosphere, habitat, and climate.

Lastly, Dr. Eaton mentioned the principal diseases which appeared to be independent of the above-nsmed influences, and not assignable to any known cause, such as tumours, tetanus, linear atrophy of the kin, fragilitas ossium, mollities ossium, and other widely distributed or purely local diseases.

The lecturer concluded by stating that he hoped his brief review of the researches of distinguished modern authorities would render more definable to the minds of his audience, as it had already to his own mind, knowledge which might hitherto have been somewhat vague, and might henceforth prove suggestive of topics which waited for investigation by the medical profession.

\section{ON THE EFFECTS OF DENTAL DISEASE.}

Delivered at the Annwal Meeting of the Bath and Bristol Branch. By C. GAINE, M.R.C.S., President of the Branch.

MR. Gaine announced that his aim, throughout the address, would be to direct the attention of the various practitioners to some morbid lesions and important reflex phenomena, which were not unfrequently observed in the daily practice of medical men, and to point out to them where a properly educated practitioner of dental surgery might be of use in aiding the diagnosis of some forms of disease, which were more familiar in the course of daily work to a specialist than they could be to a general practitioner. When we thought of the wide ramifications of the fifth nerve, the distribution of which Mr. Gaine briefly described, it did not surprise us that local irritation of one set of its branches should carse widespread physiological phenomena. The fifth communicated with all the cranial nerves except, apparently; the olfactory, and it might yet be discovered that the trigeminal was, in some manner connected with the first pair.

The communications of the fifth nerve with the vagus through the tonsillar branches of the glosso-pharyngeal, which united with the palatine nerves (branches of Meckel's ganglion) were well known. Through this slender medium of communication, the only one yet made out, we frequently noted severe toothache where nn caries, or other oymptoms of inflammation, eould be detected, through stomach-derangement, which a purgative would frequently relieve, and, on the other hand, gastric disturbance from the different forms of toothache, which relief of the local cause would surely cure.

Many varieties of neuralgia affecting different nerves and nervecentres had been desoribed, but very little was definitely known about the primary origin of any of them when the pain was of an idiopathic nature. Of the nouralgias described by different writers, but few were attributed to tooth-irritation, although many kinds had been relieved or cured by the removal of a diseased tooth or toeth. $A$ fow years since, an obstinate case of chorea in a child, 8 years old, came under the lecturer's care, and was cured after the extraction of several deciduous teeth. The most common form of neuralgia affecting the fifth nerve was ticdouloureux, and this had been frequentl curcd by removing a tooth or teeth-either carious, or crowded, and impacted as to cause pressure on some nerve-filament, during the process of eruption; the offending teeth, when not carious, could only be discovered by expert sounding or tapping with a steel instrument. This delicate percussion would probably fail the first time, when no signs of periosteal inflammation could be scen, to discover the affected tooth; but at a second visit, a few days later, the cause would probably be detected. Let it not be understood that teeth were frequently the canse of this distressing malady. It arose from a variety of canses, and was probably most freyuent in women about the climacteric period ; and Mr. Gaine had not found a dental origin for hemicrania.

With regard to those cases where the teeth were primarily affected, either from overcrowding, caries, or congestion of the periodontal membrane, or from tardy eruption of the wisdom teeth, or necrosis of a tooth, or any part of the alveolar process or jaw, technical inquiry would rarely fail to detect the origin of the trouble, and prompt treatment might avert long and painful disesse and invalidism. Early attention was always particularly necessary where a fault in the teeth was suspected, causing pain or stiffness in the jaw or surrounding structures, especially if near the time for the eruption of the wisdom teeth ; for trismus was apt to set in very rapidly, and any operation that might be necessary was easiest belore the spasm of the jaw, with its full complement of teeth, had set in.

The lecturer then referred to his urn researches, already published, on trismus or purulent discharge of the antrum and nasal fossa resulting from dental and alveolar inflammation. Ho described a caso of ptosis and amaurosis associated with fractured upper molar and pus in the antrum. Removal of the stump and evacuation of the pus was followed by disappearance of the ptosis. Another case of neuralgia trismus, and sinus below the lower jaw was caused by an unerupted wisdom tooth. The removal of that tooth, with the molar next to it, cured the patient. Mr. Gaine related a remarkable instance where, after a blow over the teeth, a lady suffered from paroxysms of pain darting through the head to the back of the ear and down to the shoulder. A lower second molar, which had lost its antagonist, wes found to be tender on percussion, yet not carious. It was extracted, and the symptoms almost immediately disappeared. Mr. Gaine split the roots of the tooth, and found the dental canal of the posterior root almost obliterated. The pulp had, no doubt, been calcified for some time; and although the congestion of the periodontal membrane at the apex of the root was apparently slight, there could be no donbt that it was the cause of the mischief. This case showed how through the epinal origin of the fifth nerve, and its communication with the otic ganglion, a morbid impression could be conveyed to the brachial plexus and the ear. All the above cases showed the necessity of timely interference before sinuses had formed and burst through tho integuments of the face.

Some observations were then made upon the chronic cachexia or septicxmia seen in persons who went about for years with carions but painless teeth in their heads, or with their teeth half buried in tartar. Such patients remained in a chronic state of invalidism, until the dental mischiti was attended to. It was adinitted that very serious diseases of the nervous system, even epilepsy and tetanus, were sometimes traced to dental affections. Mr. Gaine then spoke of epulis, cleft palate, and epithelioma of the gums.

The lecturer, in conclusion, referred to the necessity of specialism, as medical science was too wide to be taken up in its entirety as a profession. He adrocated, however, the thorough education of dental students in all those branches of science studied by other students of medicine. It was very advisable for the dentist to take a surgical diploma, and it would be better for the public when his scientific education reached such an adnitted degree of perfection as to enable him to practise preventive dentistry. By examining the teeth of children and adults, just as the practitioner examined their tongues, not only would dental disorders be averted, but likewise many of the general diseases of the various forms of impaired health, of which those disorders were the cause. 